\title{
Derechos y autonomía. La hora de la igualdad en el siglo XXI
}

\section{Rights and autonomy. Time for equality in the twenty-first Century}

\author{
Álvaro Luciano Fuentealba Hernández \\ Universidad de Chile \\ afuentealba@derecho.uchile.cl
}

Recibido:01/06/18 | Aceptado: 23/11/18

RESUMEN: En el presente trabajo se analiza la sentencia del Tribunal Constitucional de Chile que confirma la constitucionalidad del artículo 102 del Código Civil de dicho país, que restringe el derecho al matrimonio a parejas de diferente sexo, desde la perspectiva de la argumentación constitucional. Se aplica el marco teórico desarrollado por J. Sieckmann para analizar el modo en que las argumentaciones desplegadas por el tribunal entran en conflicto con los principios constitucionales de autonomía, igualdad y dignidad.

PALABRAS CLAVE: derechos humanos, matrimonio igualitario, autonomía.

ABSTRACT: The paper analyze the Chilean Constitutional Court's decision that upheld the constitutionality of the Civil Code's articles which restrict the right of same sex couples to marriage, from the scope of the constitutional argumentation. The theoretical framework on fundamental rights developed by J. Sieckmann is applied in order to show the collision of the argumental lines deployed by the court with the constitutional principles of autonomy, equality and dignity.

KEY WORDS: human rights, same sex marriage, autonomy.

\section{SUMARIO}

I. Introducción. II. Los hechos de caso y las normas relevantes. III. Reconstrucción de la argumentación que propone el Tribunal. IV. Reconstrucción de las argumentaciones del fallo de mayoría. V. Reconstrucción de las argumentaciones de la ministra Marisol Peña. VI. Reconstrucción de las argumentaciones del ministro Hernán Vodanovic. VII. Análisis crítico de la sentencia. VII.1. Análisis crítico del fallo de mayoría. VII.2. Análisis crítico del voto particular concurrente de la ministra Marisol Peña. VII.3. Análisis crítico del voto disidente 
del ministro Hernán Vodanovic. VII.4. Análisis de idoneidad. VII.5. Análisis de necesidad. VII.6. Proporcionalidad en sentido estricto. VIII. Conclusiones. Bibliografía.

\section{Introducción}

En el presente trabajo se analizará la sentencia del Tribunal Constitucional de Chile, dictada en noviembre de 2011, que declaró conforme a la Constitución el artículo 102 del Código Civil, respecto del que se pedía su inaplicabilidad por inconstitucionalidad, en el marco de una acción de protección de derechos constitucionales interpuesta por parejas del mismo sexo, norma que define al matrimonio como "un contrato solemne por el cual un hombre y una mujer se unen actual e indisolublemente, y por toda la vida, con el fin de vivir juntos, de procrear, y de auxiliarse mutuamente".

El interés de esta sentencia radica en que es el primer y único pronunciamiento de la justicia constitucional chilena sobre el derecho de las personas del mismo sexo a contraer matrimonio. Su relevancia radica, además, en que a través de los fallos divididos, concurrentes y divergentes de la decisión de mayoría, que rechazó la inconstitucionalidad de la norma del Código Civil, se explicitaron las posiciones contrapuestas de los ministros, en una gama de argumentos que van desde el rechazo del matrimonio igualitario, la afirmación del matrimonio heterosexual, ligado a una concepción unívoca de familia, pasando por el reconocimiento del derecho de toda persona a formar familia, el reconocimiento de la pluralidad de concepciones de familia, pero sin otorgar amparo constitucional de dicho derecho, hasta el necesario reconocimiento de la autonomía, igualdad y dignidad de las personas de orientación homosexual, su derecho a formar familia y a contraer matrimonio.

Asimismo, es interesante analizar los juicios de ponderación de principios que se hacen. En este sentido nos preguntaremos si es posible formular a partir de este caso una regla resultado de las ponderaciones de derechos e instituciones entendidos como principios, dada la especial naturaleza de la justicia constitucional chilena, a la que nos referiremos someramente.

La metodología utilizada es la propia del análisis de la heurística 
tradicional, aplicado al estudio de la jurisprudencia, distinguiendo entre testimonio y fuente. Se realiza un análisis de fuente, propiamente tal, en términos definidos por Wilhelm Bauer (Bauer, 1952, pp. 118 y 127). Se analiza la sentencia Rol 1881 - 2010 del Tribunal Constitucional, se hace exposición de los tres argumentos relevantes presentes en dicha sentencia y se lo somete a análisis crítico en el marco de la teoría de la ponderación de Robert Alexy, pero en las variantes del modelo presentado por Jan Sieckmann.

\section{Los hechos del caso y las normas relevantes}

La Constitución Política de la República de Chile establece una acción de amparo constitucional que se denomina "acción constitucional de protección", destinada a proveer a toda persona que se halle privada, o bien sufra perturbación o amenaza en alguno de los derechos constitucionales protegidos (en general, sólo procede respecto de derechos civiles y políticos ${ }^{1}$ ), de una acción judicial rápida, que se tramita ante la Corte de Apelaciones respectiva, tribunal que tiene amplias facultades para "restablecer el imperio del derecho y asegurar la debida protección del afectado" ". En todo caso, se requiere que la actuación que priva, perturba o amenaza el derecho, sea arbitraria o ilegal.

Asimismo, el Tribunal Constitucional tiene la potestad de declarar inaplicable cualquier precepto legal contrario a la Constitución, en cualquier gestión judicial pendiente. Dicha declaración tiene efectos relativos, vale decir, el perímetro normativo alcanza sólo a las partes del juicio y al juez, a quien le queda vedado aplicar dicha ley, que, no obstante, sigue vigente para otros casos. El sistema jurisdiccional chileno no es precedentes ${ }^{3}$, como la gran mayoría de los sistemas legales basados en la tradición jurídica romano-canónica. En

1 La excepción es la protección judicial que se otorga al derecho a vivir en un medio ambiente libre de contaminación, que es un derecho colectivo.

2 Constitución Política de la República de Chile [Const.] (2005) Artículo 20 [Capítulo III].

3 Código Civil de la República de Chile, artículo $3^{\circ}$ "Sólo toca al legislador explicar o interpretar la ley de un modo generalmente obligatorio.

Las sentencias judiciales no tienen fuerza obligatoria sino respecto de las causas en que actualmente se pronunciaren." 
consecuencia, las sentencias judiciales tienen efecto relativo, vale decir, sólo se aplica la norma declarada judicialmente inter-partes. No obstante ello, si un precepto legal ya ha sido declarado inaplicable por el Tribunal Constitucional, dicha Corte puede, en sentencia posterior, declarar su inconstitucionalidad, lo que acarrea su derogación. En consecuencia, en este último caso sí tiene efectos erga omnes la referida sentencia ${ }^{4}$, es decir, respecto de todos. La sentencia de inconstitucionalidad del Tribunal Constitucional es la única excepción al efecto relativo de las sentencias en el sistema legal chileno.

La Constitución, además, establece que la soberanía del Estado está limitada por "los derechos esenciales que emanan de la naturaleza humana", estableciendo el deber de los órganos del Estado de respetar y promover tales derechos "garantizados por esta Constitución, así como por los tratados internacionales ratificados por Chile y que se encuentren vigentes". ${ }^{6}$

En concreto, esta acción constitucional de protección se presenta por tres parejas homosexuales, en contra de una Oficial del Registro Civil, funcionario competente para celebrar el contrato de matrimonio. El referido contrato está definido en el artículo 102 del Código Civil, ya citado, que lo define como la unión de un hombre y una mujer.. Una de esas parejas solicitó día y hora para la celebración de su matrimonio, solicitud que le fue denegada, en atención a la definición transcrita, por estimarse ilegal el matrimonio entre dos personas de mismo sexo. Las otras dos parejas solicitan a la misma Oficial la inscripción en el Registro Civil, y la consecuente validación en Chile, de sus matrimonios legalmente celebrados, uno en Argentina ${ }^{7}$ y otro en Canadá. La Oficial Civil niega la inscripción porque el artículo 80 de la ley $\mathrm{N}^{\mathrm{o}} 19.947$, de 17 de mayo

4 Constitución Política de la República de Chile [Const.] (2005) Artículo 93, Nº $6^{\circ}$ y $7^{\circ}$ [Capítulo VIII].

5 La Constitución de 1980 fue impuesta en un plebiscito fraudulento por la dictadura militar que gobernó Chile entre 1973 y 1990. Era originalmente una Constitución autoritaria y muy restrictiva de los derechos humanos. En el marco de las negociaciones del dictador Augusto Pinochet con la oposición democrática a su gobierno, se realizó en julio de 1989 un plebiscito para introducir 54 enmiendas a la Constitución. Una de ellas fue incorporar una referencia explícita a los tratados internacionales sobre derechos humanos, para señalar que los derechos allí establecidos eran una limitación a la soberanía del Estado.

6 Constitución Política de la República de Chile [Const.] (2005) Artículo $5^{\circ}$ [Capítulo I].

7 Sobre la situación en Argentina véase, entre muchos otros, Aldao M.; Clérico, L., (coord.). Matrimonio igualitario. Perspectivas sociológicas, políticas y jurídicas. Ed. EUDEBA, Buenos Aires, 2010.

\section{DERECHO GLOBAL. ESTUDIOS SOBRE DERECHO Y JUSTICIA}


de $2004^{8}$, ley de matrimonio civil, señala que "el matrimonio celebrado en país extranjero producirá en Chile los mismos efectos siempre que se trate de la unión entre un hombre y una mujer".

La acción de protección sostiene que con la negativa de otorgar fecha para la celebración del matrimonio y el rechazo de la inscripción de los matrimonios legalmente celebrados en el extranjero, a los requirentes se les ha privado del derecho a la igualdad ante la ley y se ha transgredido la prohibición constitucional de establecer diferencias arbitrarias?.

La Corte de Apelaciones de Santiago, substanciando el procedimiento de protección, $\mathrm{y}$ antes de pronunciar sentencia, dirige un requerimiento al Tribunal Constitucional para que declare si es inaplicable, por ser contrario a la Constitución, el artículo 102 del Código Civil chileno.

El Tribunal Constitucional acoge a trámite la acción de inaplicabilidad de la ley para el procedimiento de protección, y suspende el trámite de la acción cautelar. Los requirentes se hacen parte ante el Tribunal, y argumentan que el artículo 102 del Código Civil, ya referido, es contrario a una serie de preceptos constitucionales ${ }^{10}$.

8 Esta ley modificó la original de 1884, introduciendo el divorcio vincular, entre otras materias.

9 Constitución Política de la República de Chile [Const.] (2005) Artículo 19 Nº 2 [Capítulo III]. 10 A saber:

1.- Artículo $1^{\circ}$, inciso $1^{\circ}$

2.- Artículo $5^{\circ}$, inciso segundo, que establece el régimen de soberanía limitada por los derechos humanos consagrados en la Constitución y en los tratados internacionales ratificados por Chile y que se encuentren vigentes. La transgresión del artículo $5^{\circ}$ estaría dada porque los efectos del artículo 102 del Código Civil producirían una afectación de los siguientes derechos, establecidos en los siguientes instrumentos internacionales:2.1.Declaración Americana de Derechos y Deberes del Hombre: a) artículo II, igualdad ante la ley, sin distinción de raza, sexo, idioma, credo ni otra alguna.b) artículo VI, "toda persona tiene derecho a constituir familia, elemento fundamental de la sociedad y a recibir protección para ella”. 2.2.- Declaración Universal de Derechos Humanos: a) artículo 2.1, igualdad en el acceso a los derechos b) artículo 7, que establece la igualdad ante la ley y la igual protección de la ley, la protección contra toda discriminación que infrinja la Declaración y contra toda provocación a tal discriminación, y c) artículo 16, que establece el derecho de los hombres y las mujeres a casarse y a fundar una familia, sin distinción de raza, religión o nacionalidad; a acceder a iguales derechos en cuanto al matrimonio, durante el mismo y en caso de disolución, a condición de libre y pleno consentimiento; y que señala que la familia es el elemento natural y fundamental de la sociedad, y tiene derecho a protección de la sociedad y del Estado. 
Antes de entrar al análisis de la sentencia, es del caso referirse al principio de igualdad y no discriminación como ha sido entendido por el sistema internacional de protección de los derechos humanos. En esta materia ha habido copiosa jurisprudencia de todos los organismos internacionales especializados en derechos humanos, tanto del sistema universal, como de los subsistemas regionales. El principio de igualdad y no discriminación ha sido reconocido como base del Estado de derecho, en la reciente Declaración de la Reunión de Alto Nivel sobre el Estado de Derecho, que estableció que todas las personas, instituciones y entidades, públicas y privadas, incluido el propio Estado, están obligadas a acatar leyes justas, imparciales y equitativas, y tienen derecho a igual protección de la ley, sin discriminación, y se estableció el compromiso de respetar la igualdad de derechos de todos, sin distinción por motivos de raza, sexo, idioma o religión ${ }^{11}$.

2.3.- Convención Americana de Derechos Humanos:

a) artículo 17 , sobre protección a la familia, b) artículo 24, que establece la igualdad ante la ley, y el derecho, sin discriminación, a igual protección de la ley.

2.4.- Pacto Internacional de Derechos Económicos, Sociales y Culturales: a) artículo 2.2, que establece la obligación de garantizar el ejercicio de los derechos del Pacto, sin discriminación alguna por motivos de raza, color, sexo, idioma, religión, opinión política o de otra índole, origen nacional o social, posición económica o cualquier otra condición social, b) artículo 10, la obligación de conceder amplia protección a la familia, especialmente para su constitución.

2.5.- Pacto Internacional de Derechos Civiles y Políticos:

a) artículo 2.1, que establece la obligación de respetar y garantizar los derechos reconocidos en el Pacto, sin distinción de raza, sexo, idioma, religión, opinión política o de otra índole, origen nacional o social, posición económica, nacimiento o cualquier otra condición social.

b) artículo 3, que obliga a los Estados Partes a garantizar a hombres y mujeres la igualdad en el goce de todos los derechos civiles y políticos enunciados en el Pacto.

c) artículo 23, que confiere a la familia protección de la sociedad y del Estado, reconoce el derecho del hombre y de la mujer a contraer matrimonio y a fundar una familia y que obliga a los Estados a asegurar la igualdad de derechos y de responsabilidades de ambos esposos.

3.- Artículo 19, "la Constitución asegura a todas las personas": $N^{\circ} 2$, la igualdad ante la ley. Se prohíben los grupos privilegiados, y se establece la igualdad entre hombres y mujeres. $\mathrm{N}^{\mathrm{o}} 3$, la igual protección de la ley en el ejercicio de sus derechos. $\mathrm{N}^{\mathrm{o}} 4$, el respeto y protección a la vida privada y a la honra de la persona y su familia. $\mathrm{N}^{\circ} 9$, el derecho a la protección de la salud. $\mathrm{N}^{\circ} 18$, el derecho a la seguridad social. $\mathrm{N}^{\circ} 24$, el derecho de propiedad. $\mathrm{N}^{\circ} 26$, la seguridad de que los preceptos legales que por mandato de la Constitución regulen, complementen o limiten las garantías que establece, no podrán afectar los derechos en su esencia, ni imponer condiciones, tributos o requisitos que impidan su libre ejercicio.

$1167^{\circ}$ Periodo de Sesiones de la Asamblea General de Naciones Unidas, 24 de septiembre de 2012. 
En las últimas dos décadas, el desarrollo del sistema universal de protección de los derechos humanos en materia de igualdad, ha sido notable. El marco jurídico internacional de los derechos humanos contiene instrumentos internacionales para combatir formas específicas de discriminación, incluida la que afecta a pueblos indígenas, migrantes, minorías, personas con discapacidad, la mujer, la discriminación racial y religiosa, o la que está basada en orientación sexual y género.

Ya en 2010, en un discurso histórico sobre la igualdad de las personas lesbianas, gay, bisexual y transgénero (LGBT) pronunciado en Nueva York, el Secretario General de las Naciones Unidas Ban Ki-moon pidió que se adoptaran medidas contra la violencia y la discriminación de que eran objeto las personas LGBT: "Como hombres y mujeres de conciencia, rechazamos la discriminación en general y en particular la discriminación basada en la orientación sexual y la identidad de género. (...) donde existan tensiones entre las actitudes culturales y los derechos humanos universales, los derechos deben prevalecer"12.

En el sistema regional interamericano de protección de los derechos humanos ha habido también avances notables sobre la materia. El antecedente más notable en el último tiempo es la Opinión Consultiva oc-24/17 de 24 de noviembre de 2017, solicitada por la República de Costa Rica. Cuando se refiere al principio de igualdad y no discriminación, hace suya la definición del Comité de Derechos Humanos de Naciones Unidas: "toda distinción, exclusión, restricción o preferencia que se basen en determinados motivos, como la raza, el color, el sexo, el idioma, la religión, la opinión política o de otra índole, el origen nacional o social, la propiedad, el nacimiento o cualquier otra condición social, y que tengan por objeto o por resultado anular o menoscabar el reconocimiento, goce o ejercicio, en condiciones de igualdad, de los derechos humanos y libertades fundamentales de todas las personas"13. Pero lo más relevante en este caso, es que ha señalado que implicaría discriminación "artificial" desconocer el derecho a formar familia y a la protección del vínculo familar por parte del Estado a

12 Discurso inaugural del $65^{\circ}$ Periodo de Sesiones de la Asamblea General de las Naciones Unidas.

13 Opinión consultiva OC-24/17 de 24 de noviembre de 2017 solicitada por la república de Costa Rica identidad de género, e igualdad y no discriminación a parejas del mismo sexo, página 33. 
las personas del mismo sexo, siendo accesorio el hecho que el matrimonio sea un derecho reconocido a un hombre y a una mujer ${ }^{14}$. Finalmente en la parte concluyente de la opinión consultiva, en su numeral 8, establece (con un voto en contra) que "8. De acuerdo a los artículos 1.1, 2, 11.2, 17 y 24 de la Convención es necesario que los Estados garanticen el acceso a todas las figuras ya existentes en los ordenamientos jurídicos internos, incluyendo el derecho al matrimonio, para asegurar la protección de todos los derechos de las familias conformadas por parejas del mismo sexo, sin discriminación con respecto a las que están constituidas por parejas heterosexuales, en los términos establecidos en los párrafos 200 a $228 " 15$.

En este contexto resulta singular que la jurisprudencia constitucional chilena se mantenga inmutable e impermeable a lo que está ocurriendo en el mundo y en el sistema universal y regional de protección de los derechos humanos, en lo relativo al derecho al matrimonio igualitario. Los estándares argumentativos que ha establecido la Corte Interamericana de Derechos Humanos son muy interesantes en orden a cómo este derecho pasa de ser un derecho humano específico, a partir de su polémica consideración como derecho de autonomía.

A continuación expongo los argumentos del Tribunal Constitucional chileno, en su sentencia de 2011 para terminar con formulaciones críticas, a partir de la teoría de Jan Sieckmann (2012).

\section{Reconstrucción de la argumentación que propone el Tribunal}

El Tribunal Constitucional resolvió por la mayoría de sus integrantes ${ }^{16}$ que la forma de plantear la cuestión de inconstitucionalidad era errónea, por tanto rechazó la acción sin referirse al fondo de la misma. No obstante ello, de los diez

14 OC-24/17, página 77 a 80 (numerales 178 a 200).

15 OC-24/17, página 88 (Opinión $\mathrm{N}^{\circ} 8$ ).

16 [https://www.tribunalconstitucional.cl/ver2.php?id=2213]. 
ministros del Tribunal, hubo cuatro votos particulares concurrentes que añadieron matices muy importantes a la decisión, tomando posiciones jurídicas radicalmente diferentes acerca de la legitimidad o ilegitimidad del amparo constitucionalidad a las parejas del mismo sexo, y un voto disidente que fue partidario de acoger la solicitud, por estimar que el matrimonio circunscrito a un contrato entre un hombre y una mujer vulneraba la Constitución porque afectaba, entre otros, la dignidad y los derechos de autonomía de las personas homosexuales. Esto es notable, ya que generalmente el Tribunal tiende a evitar que existan votos divididos. El que haya pasado así en este caso, significa que la discusión tuvo matices que impidió tener una sola opinión jurídica, lo que demuestra que fue una decisión polémica y no unívoca.

Reconstruiré los argumentos del voto de mayoría, que esencialmente recurre a elementos formales para rechazar el requerimiento, situación bastante cuestionable en el ejercicio de la justicia constitucional. El análisis procurará exponer la carencia de ponderaciones de principios que tiene la sentencia, lo que a mi juicio la vuelve errónea. Asimismo, haré una comparación de las argumentaciones de la ministra Marisol Peña, quien representa la posición más conservadora, con las del ministro Hernán Vodanovic, cuyos argumentos son los más progresistas del fallo. Esto es útil a efectos de reforzar la distinción entre derechos de autonomía y derechos humanos específicos, como asimismo, la diferencia entre derechos como principios y derechos definitivos (Sieckmann, 2012, p. 638-641), a la que me referiré en el análisis crítico de la sentencia.

\section{Reconstrucción de las argumentaciones del fallo de mayoría}

En primer lugar, el Tribunal señala que en el requerimiento de inaplicabilidad por inconstitucionalidad, la Corte de Apelaciones de Santiago no señala la forma específica en que el artículo 102 del Código Civil entraría en contradicción con la Constitución.

El asunto debatido, entonces, sería si el artículo 102 del Código Civil 
violaría la garantía constitucional de la igualdad ante la ley, contenida en el artículo 19, № 2 de la Constitución, en tanto sólo permite la norma del Código el matrimonio entre un hombre y una mujer.

Luego, se refiere a la llamada "reserva legal", es decir, que tanto los efectos como la regulación de las proyecciones del matrimonio son propios de la ley y no de la Constitución.

Señala que no puede dictarse sentencia estimatoria, ya quelainaplicabilidad por inconstitucionalidad de la ley es un control concreto de constitucionalidad, de modo tal que, de acogerse la inaplicabilidad, sólo se excluiría la aplicación del artículo 102, que define el matrimonio, subsistiendo todas las demás normas legales que regulan la institución matrimonial, que constituyen un corpus jurídico mucho más amplio que la sola definición del matrimonio ${ }^{17}$.

No puede prosperar el requerimiento, porque pretendería que se formule de forma integral un conjunto completo de normas que regularían el matrimonio, lo que es competencia del legislador y no de la justicia constitucional. Se estaría pidiendo que se regule positivamente un conjunto de normas acerca del matrimonio, de forma distinta a como están reguladas en las leyes respectivas, competencia que no tiene el Tribunal Constitucional. Lo que se impugna no es sólo el artículo 102 del Código Civil, sino la aplicación de "un estatuto jurídico complejo, derivado del vínculo matrimonial entre hombre y mujer"18. La pretensión de los peticionarios de que se les reconozca el instituto matrimonial no es, en consecuencia, de competencia del Tribunal Constitucional, sino de los poderes colegisladores, el Presidente y el Congreso Nacional.

Por otra parte, al no haber solicitado la inaplicabilidad del artículo 80 de la ley de matrimonio civil, referida a la inscripción en Chile de matrimonios celebrados en el extranjero, siempre que se trate de una unión entre un hombre y una mujer, si se declarara la inaplicabilidad del artículo 102 del Código Civil, no tendría efectos para las peticiones de las dos parejas cuyos matrimonios celebrados en Canadá y Argentina se pretendían inscribir y validar en Chile.

17 Fojas 9 de la sentencia. Sentencia $1881-2010$. 18 Tribunal Constitucional de Chile, Pleno. (3 de noviembre de 2011). Sentencia 1881-2010. 


\section{Reconstrucción de las argumentaciones de la ministra Marisol Peña}

La ministra Peña inicia su argumentación a partir de una pretendida concepción constitucional de la familia. La familia tiene un estatuto constitucional. El matrimonio tiene, además, un estatuto constitucional que constituye un mandato para que el legislador lo regule. Se refiere a las funciones que cumple la familia, que la hacen merecedora de protección constitucional y legal: equidad intergeneracional, transmisión de valores culturales, hábitos y socialización $\operatorname{primaria}^{19}$.

Señala que el matrimonio entre hombre y mujer es la base esencial de la familia amparada por la Constitución, porque las funciones asignadas por el legislador a la familia sólo pueden ser cumplidas por un matrimonio heteronormativo, fundamentalmente, la de procrear, resultando decisiva la procreación como forma de conservación de la sociedad.

Asimismo, señala que la definición del matrimonio como la unión entre un hombre y una mujer no sólo está amparada por la Constitución, al remitir a la codificación civil su definición y sus funciones como generador de la familia, núcleo fundamental de la sociedad. La ministra Peña sostiene que es un derecho amparado por todos los instrumentos internacionales de derechos humanos citados por los peticionarios, que tienen aplicación en Chile por mandato del artículo $5^{\circ}$, inciso $2^{\circ}$ de la Constitución.

Señala que tanto la Declaración Universal de Derechos Humanos, como el Pacto Internacional de Derechos Civiles y Políticos, y la Convención Americana de Derechos Humanos, regulan el derecho al matrimonio y la protección de la familia, siempre que se trate de la unión entre un hombre y una mujer ${ }^{20}$. El matrimonio entre un hombre y una mujer es un derecho humano, de acuerdo a estos instrumentos y de acuerdo a la ley de matrimonio civil. Si es un derecho humano, debe realizarse conforme a los valores y fines constitucionales, entre los

19 Tribunal Constitucional de Chile, Pleno. (3 de noviembre de 2011). [Ministra Marisol Peña].

20 Tribunal Constitucional de Chile, Pleno. (3 de noviembre de 2011). [Ministra Marisol Peña]. 
que está la consideración de la familia como núcleo fundamental de la sociedad.

Concluye sosteniendo que el mandato de regulación del matrimonio que la Constitución otorga al legislador, debe interpretarse armónicamente y en forma sistemática, por tanto, sólo entendida como una unión entre un hombre y una mujer, porque el legislador no puede regularlo al margen de los valores y principios expresamente consagrados en la Carta Fundamental.

\section{Reconstrucción de las argumentaciones del ministro Hernán Vodanovic}

El ministro Hernán Vodanovic es el único que sostiene un fallo disidente. Estuvo a favor de acoger la acción, y declarar la inaplicabilidad del artículo 102 del Código Civil, por ser contrario a la Constitución.

Señala que el argumento con arreglo al cual la declaración de inaplicabilidad no podría formularse, porque implicaría la modificación íntegra de todas las normas que regulan la institución matrimonial, y que no se han citado otras, no es un argumento de peso.

En efecto, siempre se produce aquello cuando el tribunal constitucional realiza este pronunciamiento, y, por lo demás, tiene sólo efecto relativo a las partes del juicio, subsistiendo las normas en el ordenamiento jurídico.

Sostiene, asimismo, el ejercicio de la justicia constitucional no puede ser limitada por cuestiones de forma. Dada la trascendencia del asunto y el carácter consultivo que tiene el requerimiento del juez al Tribunal, hay que pronunciarse respecto del fondo, por la trascendencia de la cuestión.

Señala que un precepto legal puede adecuarse a las disposiciones constitucionales de su época, pero que pasados los años y en este caso, más de un siglo, perfectamente puede entrar en contradicción con el "conjunto de valores, principios y derechos fundamentales que la Constitución consagra, tal cual son 
entendidos en este otro momento"21.

Para elucidar las normas constitucionales, más que buscar la voluntad del constituyente, lo que debe hacerse es reconocer cuál es la orientación y sensibilidad que prevalece hoy en día, "cómo se resuelven las diferencias o conflictos de valores y principios en este momento y cuáles son los que ostentan preeminencia",22.

Luego, entra al análisis del conflicto de principios. Señala que por una parte, la única exclusión del matrimonio entre iguales es el principio constitucional o bien jurídico protegido de la intangibilidad de la familia. Por otro lado, los principios y derechos que están detrás de la defensa del matrimonio igualitario son la libertad, igualdad y dignidad de las personas, así como el conjunto de derechos de la personalidad.

Así las cosas, la tensión, señala el ministro, estaría dada por una parte entre el principio constitucional de la familia y su protección, así como el reconocimiento de la autonomía de los cuerpos intermedios a través de los cuales se estructura la sociedad, y por otra, la libertad e igualdad en dignidad y derechos, el principio de servicialidad del Estado a la persona, la obligación de promover el bien común y asegurar a las personas su máximo desarrollo material y espiritual posible, y la promoción de la integración armónica de todos los sectores de la población, y la obligación de asegurar a todas ellas la participación en la vida nacional con igualdad de oportunidades.

Para sus protagonistas, la materialización del matrimonio entre personas del mismo sexo implica la plena realización de los valores de libertad, igualdad y dignidad humanas, por tanto, si se entiende que hay oposición con el valor o el principio de la familia, debe hacerse una ponderación razonable de dichos principios, y la única que cumple esos presupuestos es la que de preeminencia a la dignidad y derechos humanos de las personas, por trascendente y respetable

21 Tribunal Constitucional de Chile, Pleno. (3 de noviembre de 2011). Sentencia 1881-2010. [Ministro Hernán Vodanovic].

22 Tribunal Constitucional de Chile, Pleno. (3 de noviembre de 2011). Sentencia 1881-2010. [Ministro Hernán Vodanovic]. 
que sea la institución de la familia.

El problema cede, entonces, ponderando los principios, a favor del matrimonio igualitario, ya que realizan en la mayor medida posible, de acuerdo a las condiciones fácticas y jurídicas, los principios de libertad, igualdad y dignidad, en contra del principio de protección de la familia, que no por ello queda sin aplicación. Debe argumentar, entonces, en qué situación queda la familia, como principio contrario en tensión.

Para abordar este problema, el ministro Vodanovic señala que lo que se oculta tras todas las argumentaciones que afirman la protección de la familia, califican a la homosexualidad como enfermedad o niegan el concepto de orientación sexual, es una profunda homofobia. Todas estas expresiones homofóbicas son ofensivas a la dignidad humana y perpetra un trato vejatorio a las personas con una orientación sexual diversa. Sostiene que es una realidad demostrada por encuestas de opinión ${ }^{23}$, que en Chile hay un alto grado de discriminación en contra de las personas homosexuales. En relación con lo anterior, el ministro Vodanovic se pregunta si la prohibición del matrimonio entre iguales evita o refuerza la referida discriminación.

Señala Vodanovic que superadas por la historia otras discriminaciones odiosas a grupos de seres humanos, en la actualidad la discriminación por orientación sexual es una de las más agudas contra una minoría, sólo comparable con la que sufren los inmigrantes. En razón de ello, la pregunta jurídica es ¿constituye una discriminación arbitraria la exclusión de la institución del matrimonio a las personas del mismo sexo?

Afirma que la procreación dentro del matrimonio, en los hechos, es irrelevante, sobre todo si se considera, por ejemplo, que en Chile la mayoría de los nacimientos se produce fuera del matrimonio. La finalidad del matrimonio es, entonces, el afecto, la solidaridad y asistencia recíproca que se deben entre los cónyuges. Si esto es así, debe invertirse la carga de la argumentación, debiendo los sostenedores de la exclusividad del matrimonio heterosexual exponer razones

23 Estudios de Opinión Pública. Universidad del Desarrollo, junio de 2011.

\section{0


que así lo sostengan. Es más, para una adecuada ponderación, deben probar que la exclusión de las parejas homosexuales fortalece la unión matrimonial heterosexual, y como esto no es así, la prohibición no es necesaria para proteger los derechos de los que sí pueden casarse.

Sostiene Vodanovic que la Constitución no establece una concepción de familia ni de matrimonio, ya que reconoce la diversidad y pluralismo de la sociedad chilena. Asimismo, tiene una serie de reglas que obligan a la igualdad de trato a todas las personas. La igualdad ante la ley implica el respeto a la dignidad de las personas y el reconocimiento de la autonomía de cada una de ellas. Este trato igualitario y respetuoso exige el acceso de todas las personas a la institución matrimonial, ya que el Estado tiene el deber de promover estas distintas opciones de vida compatibles con el bien común. Negar la institución matrimonial a un grupo implica negarles la dignidad de la que son merecedores de acuerdo a la Constitución. Estas diferencias no son sólo simbólicas, sino que el estatus que otorga el matrimonio implica una serie de derechos adicionales de los que están excluidas las personas del mismo sexo.

En conclusión, para el ministro Hernán Vodanovic, si el Estado niega el acceso al matrimonio a las parejas del mismo sexo, incurre en una exclusión incompatible con el respeto a la dignidad humana, la autonomía individual y la igualdad ante la ley, al mismo tiempo que incumple con el mandato de proteger a la familia, entendida en términos amplios.

\section{Análisis crítico de la sentencia}

\section{VII.1. Análisis crítico del fallo de mayoría}

Los cuestionamientos que en doctrina se han formulado a la justicia constitucional se refieren al problema de legitimidad que implica que un órgano contramayoritario pueda dejar sin efecto las decisiones democráticas que la mayoría adopta en las leyes, al imponerse por un órgano no elegido las condiciones de la democracia (Waldron, 1999). Los defensores de la justicia constitucional contestan que lo 
que se pierde en generación democrática del derecho, se gana en defensa de derechos de las personas, ya que el principal aporte de la justicia constitucional es la mejora de la calidad del debate político de una sociedad, junto a la protección y promoción de los derechos humanos (Dworkin, 1996).

Por esta razón, resulta sorprendente el fallo de mayoría del Tribunal Constitucional que se ha analizado en el acápite anterior, ya que antepone elementos formales para no entrar en la resolución del asunto, a saber, la omisión en el requerimiento del juez de la inaplicabilidad del artículo 80 de la ley de matrimonio civil, referida a las reglas sobre inscripción en Chile de matrimonios válidamente celebrados en país extranjero, sumado a la carencia de competencias del Tribunal Constitucional para formular positivamente reglas que reemplazasen el conjunto normativo regulatorio de la institución matrimonial, que no se circunscribe sólo al artículo 102 del Código Civil.

Señalan que la Corte de Apelaciones no habría señalado en forma específica en qué forma el artículo 102 violaría la Constitución, lo que dejaba al Tribunal en la imposibilidad de pronunciarse, en circunstancias que la afectación saltaba a la vista: tres parejas recurrentes se veían imposibilitadas de acceder al estado civil de casadas ante la legislación chilena, y la pregunta a responder era si dicha situación contradice o no el orden constitucional chileno. Asimismo, la propia naturaleza de la justicia constitucional invitaba a los ministros a pronunciarse respecto al fondo, ya que de acuerdo a la forma de entender las disposiciones de la Constitución, sobre todo en cuanto al contenido normativo de los derechos de autonomía que establece y las remisiones a los tratados internacionales de derechos humanos, los bordes del problema jurídico estaban bastante claros, y las discrepancias debían ser sujetas a argumentación.

El argumento con arreglo al cual el Tribunal carecería de competencias para pronunciarse y que compete al legislador corregir la situación viene a darles la razón a los detractores de la justicia constitucional.

¿Es el derecho al matrimonio igualitario un derecho a priori? Siguiendo a Sieckmann, esa es la pregunta relevante (2012, p. 640). Claramente no sería un derecho de autonomía, pero en virtud de los derechos de autonomía, debe 
reconocerse el derecho de todo sujeto autónomo a expresar demandas normativas como aquella, que a priori, convengamos, es sólo un interés. Ese interés ¿está protegido por un derecho humano? En virtud de la igualdad y la autonomía de cada persona, que fluyen del básico concepto de dignidad, debo poder someter a juicio la validez moral de mi pretensión y mi demanda de que se transforme en validez normativa.

1. Validez jurídica prima facie ¿Está conectado el matrimonio igualitario con algún derecho fundamental?

2. Validez jurídica definitiva ¿Entra en conflicto con otro derecho? ¿Qué parte de la pretensión se encuentra dentro del marco del ordenamiento jurídico? (Sieckmann, 2012, p. 643).

En función de este esquema taxonómico, se podría haber fundado el derecho humano específico al matrimonio entre personas del mismo sexo, o bien, con argumentos sólidos haber rechazado la pretensión normativa, sobre la base de la inconexión de los derechos de autonomía con un derecho humano específico al matrimonio igualitario. Nada de eso hizo el Tribunal Constitucional, lo que es lamentable desde el punto de vista de la deseable densidad de precedentes que se espera del ejercicio de la justicia constitucional, en especial si estimamos beneficiosa la existencia de reglas resultado de la ponderación.

\section{VII.2. Análisis crítico del voto particular concurrente de la ministra Marisol Peña}

La ministra Peña hace una interpretación literal, tanto del artículo 102 del Código Civil, como de los instrumentos internacionales de protección de los derechos humanos que se refieren al matrimonio, y en base a ello concluye que es un derecho siempre que se contraiga entre un hombre y una mujer.

La Convención de Viena sobre Derecho de los Tratados y todas las normas de interpretación de los instrumentos internacionales citados excluyen la interpretación literal, justamente porque el objeto y propósito del tratado 
es básico para la interpretación de las normas de derechos humanos, como asimismo, la interpretación pro hominis descarta de plano la exégesis literal del texto. En efecto, sólo para citar algunas de estas reglas, la interpretación de ellas debe hacerse de buena fe, de acuerdo a su objeto y finalidad, no a lo literal de las palabras, y nunca en el sentido de restringir los derechos reconocidos en los instrumentos. $^{24}$

No obstante ello, si hacemos un análisis literal, hay una diferencia fundamental en la regulación de todos los instrumentos internacionales y el Código Civil chileno, y es que dichos instrumentos reconocen al "hombre y a la mujer" el derecho al matrimonio, no al "hombre con la mujer" o viceversa. Vale decir, es un derecho que literalmente puede ser entendido para la mujer que podría optar a contraer matrimonio con otra, y al hombre que podría casarse con otro hombre. Esa es la lógica de los derechos individuales y su regulación internacional.

En segundo lugar, la ministra concluye que el matrimonio es un derecho humano. La consecuencia que se sigue de ello, es que debe interpretarse a la luz de los valores y principios constitucionales, entre los que está la concepción de la familia como núcleo fundamental de la sociedad. Ello implicaría un límite constitucional para el legislador a la hora de regular la institución matrimonial: no puede introducir el matrimonio entre personas del mismo sexo.

Se aprecia un salto lógico en la conclusión, extraída del supuesto mandato internacional y constitucional de establecer o reconocer sólo el matrimonio heterosexual a partir de los enunciados normativos que establecen el concepto de familia como núcleo básico de la sociedad, y los mandatos de protección a dicha institución.

El argumento se resumiría en que "como la familia es el núcleo fundamental de la sociedad, y una de sus funciones es la procreación, para la perpetuación física y espiritual de la humanidad y la sociedad, el matrimonio

24 Art. 31 de la Convención de Viena sobre Derecho de los Tratados. Art. $5^{\circ}$ del Pacto Internacional de Derechos Civiles y Políticos. Art. 29 de la Convención Americana de Derechos Humanos. 
es entre un hombre y una mujer. El matrimonio es un derecho humano, por tanto el legislador debe regularlo siempre considerando que sea entre hombre y mujer, ya que debe hacerlo a la luz de los valores y principios constitucionales". Se aprecia, en efecto, un déficit de saturación de argumentos para que fluya como consecuencia lógica del principio de protección a la familia (no distingue claramente la ministra si es un valor o un principio constitucional, ya que trata indistintamente ambas categorías conceptuales, referidas a la familia) ${ }^{25}$.

En efecto, si la ministra Peña sostiene una pretensión de universalidad de un supuesto derecho humano al matrimonio entendido sólo para un hombre y una mujer, debe demostrar argumentativamente dicha pretensión normativa en base a derechos de autonomía, lo que nos parece imposible. Si ese derecho al matrimonio es un principio, tampoco puede seguirse lógicamente una prohibición al legislador, ya que sólo implicaría que los órganos públicos ponderarán si le reconocen validez jurídica definitiva o no al derecho en cuestión (Sieckmann, 2012, p. 641). Y resta argumentar, además, por qué el establecimiento del derecho al matrimonio igualitario afectaría el derecho al matrimonio entre un hombre y una mujer, aún si estimáramos que de la definición explícita actual del derecho humano al matrimonio se coligiese naturalmente la diferencia de sexos de los contrayentes, cuestión de suyo controvertida ${ }^{26}$.

En el voto de la ministra Peña aparecería una regla resultado de la ponderación, que tampoco puede sostenerse, ya que no hay densidad de precedentes sobre la materia, por tanto el sentenciador, en este caso, está obligado a ponderar, y antes que ello, a identificar los derechos en conflicto, y la intensidad de la restricción del derecho en abstracto y en concreto, para determinar la relación de prioridad (Clérico, 2010, p. 286). Nada de eso se hace, por tanto podemos concluir que existe un severo déficit argumental.

25 Considerando $7^{\circ}$ del mismo voto particular concurrente.

26 Controversia que aparece claramente en la jurisprudencia citada en la sentencia en análisis: a) sobre matrimonio: Corte Constitucional de Sudáfrica, sentencia de 1 de diciembre de 2005, considerando 102; Caso Schalk and Kopf v. Austria. Corte Europea de Derechos Humanos; Caso Loving v. Virginia. Corte Suprema Federal de los Estados Unidos de América; b) sobre familia: "no es posible dar una definición uniforme del concepto", Observación General № 19, comentarios generales adoptados por el Comité de los Derechos Humanos de Naciones Unidas, 1990, UN 2, HRI/GEN 1 Rev. 7 at 171. 
En ningún momento se refiere o aprecia que puede haber una colisión de derechos o de principios, o de derechos humanos entendidos como principios que operen argumentativamente en forma opuesta, ya sea como mandatos de optimización (Alexy, 2010, p. 458), o como resultantes de demandas normativas y juicios de sujetos autónomos, derechos humanos específicos o derechos a posteriori (Sieckmann, 2012, p. 637). No hay alusión a los derechos de igualdad y autonomía, y a la dignidad de los recurrentes, que es la base del requerimiento, y que constituyen el núcleo de la cuestión de constitucionalidad debatida.

\section{VII.3. Análisis crítico del voto disidente del ministro Hernán Vodanovic}

En el voto disidente del ministro Vodanovic se aprecia un juicio de ponderación en que se pueden aplicar las reglas de la teoría de la argumentación jurídica, en una escala triádica, para analizar la proporcionalidad en sentido amplio, es decir, el análisis de idoneidad, de necesidad y la ponderación en sentido estricto (Alexy, 2010, p. 468).

En primer lugar, determina que en el caso en análisis se presenta una tensión entre el principio constitucional de protección a la familia (que sustentaría la defensa de la exclusividad del matrimonio heterosexual), y los derechos de libertad, igualdad y protección a la dignidad de las personas (que están en juego con la exclusión del matrimonio igualitario). En razón de ello, la exclusión de matrimonio igualitario sería una omisión del Estado que implicaría una afectación a los derechos de autonomía por defecto o acción insuficiente.

\section{VII.4. Análisis de idoneidad}

¿Es idónea para la protección de la familia, incluso para la protección del matrimonio heterosexual, la exclusión del matrimonio igualitario? El ministro Vodanovic señala que no está justificado el exceso (de supuesta protección a la institución de la familia) que las parejas del mismo sexo deben soportar. La no realización del principio opuesto en este caso es total, por tanto la afectación al derecho es grave (Clérico, 2010, p. 261), y no afecta en nada a la familia 
ni al matrimonio heterosexual la incorporación de las parejas homosexuales a la institución del matrimonio, por tanto no es idónea la medida ya que "la prohibición no es necesaria para proteger los derechos de aquellos que sí pueden casarse" 27 .

\section{VII.5. Análisis de necesidad}

En relación con este punto, el voto disidente nada señala, probablemente porque su autor estima irrelevante referirse a la necesidad o la existencia de medios alternativos que puedan realizar el principio de protección a la familia en la mayor medida posible, sin afectar el derecho de las personas del mismo sexo a casarse. El desarrollo del análisis de necesidad hubiese sido interesante para colmar los argumentos a favor de la existencia del derecho de las personas del mismo sexo a contraer matrimonio, puesto que obligaría a analizar la existencia o no de medios alternativos menos gravosos (Clérico, 2009, p. 104), lo que también hubiese servido para elevar los estándares de argumentación a favor de las razones de optimización del principio de protección de la familia.

\section{VII.6. Proporcionalidad en sentido estricto}

En esta parte el ministro Vodanovic realiza un juicio de ponderación en sentido estricto, ya que establece que cuanto más intensa es la restricción, en este caso grave o total, ya que se está negando el derecho al matrimonio, más importantes deben ser las razones para sostener la importancia del principio de protección a la familia, y concluye que no hay razones suficientemente importantes para, so pretexto de cumplir la obligación del Estado de dar protección a la familia, restringir gravemente la libertad, igualdad y dignidad de las parejas del mismo sexo, que quedan excluidas de la institución matrimonial.

En otras palabras, sería una promoción muy fuerte de la protección a la familia, si por el otro lado, se niega totalmente el derecho a contraer matrimonio a

27 Considerando $5^{\circ}$ del voto disidente. 
uno de los grupos que en la actualidad soportan graves formas de discriminación, como la comunidad LGBTI. Tomando el principio de igualdad, como mandato de optimización, el ministro se pregunta si la prohibición del matrimonio igualitario promueve o mitiga la discriminación de esta "categoría sospechosa" de individuos, y concluye que la profundiza, por tanto el imperativo de realización del principio de igualdad, en su forma de no discriminación, implica su realización en la mayor medida posible, de acuerdo a las circunstancias fácticas y jurídicas (Alexy, 2010, p. 459), y para eso debe permitirse el matrimonio igualitario, a través de la declaración de inaplicabilidad por inconstitucionalidad del artículo 102 del Código Civil.

En conclusión, considera que de rechazarse la acción, se produce una restricción grave a la libertad, igualdad y dignidad de los peticionarios, no habiendo una promoción del principio de protección a la familia que justifique tal restricción. En consecuencia, el matrimonio heterosexual exclusivo, viola la Constitución.

\section{Conclusión}

La posición institucional del órgano adjudicador se define por su obligación de resolver los asuntos controvertidos, de hacerlo conforme a derecho, es decir, a las reglas y principios del derecho vigente, pero sobre todo, por su obligación de fundar dicha decisión.

Tratándose de adjudicar en materias que dicen relación con los derechos humanos, es decir, con derechos que han encarnado pretensiones normativas que realizan la dignidad humana, basada en la igualdad y la autonomía, la obligación de fundamentación de las decisiones judiciales cobra mucha mayor relevancia.

Hemos podido analizar una de las decisiones más polémicas pero interesantes de la justicia constitucional chilena en el último tiempo y someter a crítica el desarrollo de sus argumentos. Lamentablemente descubrimos que aún pesan más en la jurisprudencia del Tribunal los criterios defensores de instituciones impersonales y abstractas, difíciles de conectar en concreto con la 
afirmación de derechos, que los criterios de defensa y amparo de las personas, argumento central de los defensores de la adjudicación constitucional, y que conspira contra la aspiración de tener reglas resultado en la ponderación de derechos como principios, dada la escasa densidad de precedentes en tal sentido.

A lo mejor, como señala Bruce Ackerman (2011), no son los precedentes lo que hacen falta, sino un movimiento político que legitime las pretensiones de una comunidad que necesita de reconocimiento jurídico de sus aspiraciones e intereses, para que se transformen en derechos, o un nuevo relato constitucional de una nueva generación de juristas, que logre remecer las bases de la justicia constitucional en la lucha por los derechos civiles, ya que "la historia constitucional avanza en ciclos... cada generación ha mirado las alturas políticas para descubrir que el gobierno del momento estaba encaminándose decididamente hacia la opresión. Una y otra vez se ha dado la misma respuesta: organizar un movimiento opositor... y redefinir el futuro constitucional... (Ackerman, 2011, p. 40)".

\section{Bibliografia}

Ackerman, Bruce (2011). La Constitución Viviente. Colección Filosofía y Derecho. Madrid, Barcelona, Buenos Aires: Marcial Pons.

Alexy, R. (2010). Teoría de la Argumentación Jurídica. La teoría del discurso racional como teoría de la fundamentación jurídica. Lima: Palestra Editores.

Bauer, W. (1952) Introducción al Estudio de la Historia. Barcelona: Bosch, $2^{\mathrm{a}}$ edición,

Clérico, L. (2009). El Examen de Proporcionalidad en el Derecho Constitucional. Buenos Aires: EUDEBA.

Clérico, L. (2010). "Hacia un modelo de ponderación orientado por reglas para la solución de conflictos entre derechos fundamentales." En Escobar García C. (Ed.) Teoría y Práctica de la Justicia Constitucional. Serie Justicia y Derechos Humanos. Neoconstitucionalismo y Sociedad (p. 253-296). Quito: Ministerio 


de Justicia y Derechos Humanos.
Dworkin, R. (1996). Freedom 's Law: The moral Reading of the American
Constitution. Cambridge: Harvard UniversityPress.
Sieckmann, J. (2012) “Derechos Humanos y Autonomía”. En Capaldo, G.,
Clérico, L. y Sieckmann, J. (Ed.), Internacionalización del Derecho
Constitucional, Constitucionalización del Derecho Internacional
(pp. 631-662). Buenos Aires: EUDEBA, Alexander von Humboldt
Stiftung.
Waldron, J. (1999). Law and Disagreement. Oxford: Oxford University
Press.
Constitución Política de la República de Chile [Const.] (2005)
Tribunal Constitucional de Chile, Pleno. (3 de noviembre de 2011).
Sentencia 1881-2010.

Cómo citar este artículo: Fuentealba, Á. (2019). Derechos y autonomía. La hora de la igualdad en el siglo XXI. Derecho Global. Estudios sobre Derecho Justicia, 4(11), pp. 67-90. DOI: 10.32870/dgedj.v0i11.219 